\title{
Significantly greater triglyceridemia in Black African compared to White European men following high added fructose and glucose feeding: a randomized crossover trial
}

\author{
Louise M. Goff ${ }^{1,3^{*}}$, Martin B. Whyte ${ }^{2}$, Miriam Samuel ${ }^{1}$ and Scott V. Harding ${ }^{1 *}$
}

\begin{abstract}
Background: Black African (BA) populations are losing the cardio-protective lipid profile they historically exhibited, which may be linked with increasing fructose intakes. The metabolic effects of high fructose diets and how they relate to blood lipids are documented for Caucasians, but have not been described in BA individuals.

Objective: The principle objective of this pilot study was to assess the independent impacts of high glucose and fructose feeding in men of BA ancestry compared to men of White European (WE) ancestry on circulating triglyceride (TG) concentrations.
\end{abstract}

Methods: Healthy males, aged 25-60 years, of BA $(n=9)$ and WE $(n=11)$ ethnicity were randomly assigned to 2 feeding days in a crossover design, providing mixed nutrient meals with $20 \%$ total daily caloric requirements from either added glucose or fructose. Circulating TG, non-esterified fatty acids (NEFA), glucose, insulin and C-peptide were measured over two 24-h periods.

Results: Fasting TGs were lower in BAs than WEs on the fructose feeding day $(p<0.05)$. There was a trend for fasting TG concentrations $24 \mathrm{~h}$ following fructose feeding to increase in both BA (baseline median fasting: 0.80, IQR 0.6-1.1 vs 24-h median post-fructose: 1.09, 0.8-1.4 mmol/L; $p=0.06$ ) and WE (baseline median fasting 1.10, IQR 0.9-1.5 vs 24-h median post-fructose: 1.16 , IQR $0.96-1.73 \mathrm{mmol} / \mathrm{L} ; p=0.06$ ). Analysis within ethnic group demonstrated that in TG iAUC was significantly higher in BA compared to WE on both glucose (35, IQR 11-56 vs -4 , IQR $-10-1 \mathrm{mmol} / \mathrm{L} / \mathrm{min} ; p=0$. 004) and fructose (48, IQR 15-68 vs 13, IQR $-7-38 \mathrm{mmol} / \mathrm{L} / \mathrm{min} ; p=0.04)$. Greater suppression of postprandial NEFA was evident in WE than BA after glucose feeding $(-73$, IQR $-81--52$ vs $-26, \mathrm{IQR}-48--3 \mathrm{nmol} / \mathrm{L} / \mathrm{min} ; p=0.001)$ but there was no ethnic difference following fructose feeding.

Conclusions: Understanding the metabolic effects of dietary acculturation and Westernisation that occurs in Black communities is important for developing prevention strategies for chronic disease development. These data show postprandial hypertriglyceridemia following acute feeding of high added fructose and glucose in BA men, compared to WE men, may contribute to metabolic changes observed during dietary acculturation and Westernisation.

Trial registration: The study was retrospectively registered on clinicaltrials.gov: NCT02533817.

Keywords: Ethnicity, Fructose, Insulin, Triglycerides, Postprandial

Abbreviations: BA, Black African; BMI, Body mass index; CAD, Coronary artery disease; MI, Myocardial infarction; NEFA, non-esterified fatty acids; TG, triglycerides; WC, waist circumference; WE, White Europeans

\footnotetext{
*Correspondence: louise.goff@kcl.ac.uk; scott.harding@kcl.ac.uk

'Division of Diabetes and Nutritional Sciences, King's College London,

Franklin-Wilkins Building, Stamford Street, London SE1 9NH, UK

Full list of author information is available at the end of the article
} 


\section{Background}

Ethnic-specific metabolic effects of fructose have not been described despite comprehensive literature describing the deleterious effects of high fructose diets. Populations of African ancestry have historically been characterised by a distinctly cardio-protective fasting lipid profile (low total and LDL-cholesterol, high HDL-cholesterol and low TG) $[1,2]$ and low rates of myocardial infarction (MI) [3-5]. However recent evidence recognises a changing profile of cardiovascular morbidity in young Blacks, with increasing rates of $\mathrm{MI}[6,7]$, and fasting lipids that are no longer different to Whites [8]. These changes are not explained by clinical or socioeconomic factors suggesting that lifestyle alterations may be playing a crucial role [6, 9]. Dietary acculturation of migrant populations, from a traditional diet to one that includes 'Westernised' foods is believed to play a role in the changing health profile and is characterised by high intakes of biscuits/cookies, cakes, sugarsweetened beverages and confectionary [10] leading to increased fat, saturated fat and sugar intakes [11, 12]. Acculturation and adoption of Western dietary patterns increases with the length of time since migration, and becomes more apparent in subsequent generations [13]. To this effect, within the UK population people of Black Caribbean ancestry show greater dietary acculturation than people of Black African ancestry whose migration is more recent [14]. In line with this Black Caribbeans exhibit fasting lipids that are no different to Whites however Black Africans still exhibit cardioprotective lipids [8], which may be lost as they adopt more Westernised dietary patterns.

The use of high-fructose corn syrup (HFCS) in the food industry and manufacture of sugar-sweetened beverages and confectionary has received much attention in recent years. Due to increased intake of products containing HFCS and sucrose the fructose load of the Western diet has increased significantly in recent decades [15] and it is estimated that two-thirds of dietary fructose is provided by beverages and other manufactured foodstuffs such as confectionary and only a third of fructose intake is from natural sources such as fruit and vegetables [16]. Fructose feeding has been shown to have significant effects on lipid metabolism and regulation. Studies of acute [17-22] and chronic [23] fructose feeding (usually 20-25\% of energy) show that fructose potentiates postprandial lipemia, assessed as significantly increased 24-h post-prandial TG profiles; the mechanisms responsible for these effects are not fully understood but are proposed to include increased hepatic de novo lipogenesis (DNL) and VLDL secretion, and decreased TG clearance [24]. African-Americans consume significantly more sugar and HFCS than Whites and it is estimated that 1 in 6 African-Americans are consuming more than $25 \%$ of their daily calories from added sugars compared to 1 in 11 White-Americans [25].
The metabolic effects of fructose consumption have been relatively well studied in participants of White ethnicity, however to date there are no studies that have examined the impact of high fructose diets in people of African ancestry and explored the role of fructose consumption in the changing cardiometabolic risk profile of Black populations. Using a randomised controlled crossover design we have conducted a pilot investigation to test the hypothesis that acute feeding of high fructose will potentiate significantly greater post-prandial hypertriglyceridemia in men of Black African (BA) origin compared to men of White European (WE) origin.

\section{Methods \\ Design}

A randomised crossover trial was conducted to compare the effects of $24 \mathrm{~h}$ high added fructose and high added glucose feeding (20\% of daily calories) in men of BA compared with men of WE origin. Fasting and post-prandial circulating TG, non-esterified fatty acids (NEFA), glucose, insulin and C-peptide were measured in $9 \mathrm{BA}$ and $11 \mathrm{WE}$ participants over a 24-h period on two separate days, during which they consumed three isocaloric, mixed nutrient meals accompanied by beverages sweetened with either $100 \%$ fructose or $100 \%$ glucose (Additional file 1: Table S1), in a randomised crossover fashion.

\section{Participants}

Healthy men (age range: $25-60$ y, BMI range: $18-35 \mathrm{~kg} / \mathrm{m}^{2}$ ) of WE $(n=11)$ and BA $(n=9)$ origin were recruited from the general population via research recruitment emails and newspaper advertisements. Potential participants attended the research clinic for screening of eligibility and were excluded if found to have fasting glucose in the diabetic range (fasting glucose $>7 \mathrm{mmol} / \mathrm{L}$ ), or found to have hypertension or hyperlipidaemia deemed to require immediate medical intervention (defined as: total cholesterol $>6.0 \mathrm{mmol} / \mathrm{l}$; LDL-cholesterol $>4.5 \mathrm{mmol} / \mathrm{L}$; fasting TG $>3 \mathrm{mmol} / \mathrm{L}$ ).

Ethnicity was both self-defined by the participants, and confirmed by records of parental and grandparental origin and birthplace; WE participants had at least 3 grandparents originating from countries of Europe and BA participants had at least 3 grandparents originating from countries of West Africa (Economic Community of West African States (ECOWAS) and Central African countries (e.g. Cameroon, Uganda, etc.).

The study was approved and conducted according to the standards of the King's College London Research Ethics Committee (BDM-12-13-7), and written informed consent was provided by all participants. A small remuneration was provided to acknowledge the participants' time and commitment. Data collection was conducted 
January 2013 - July 2014. The study is registered on clinicaltrials.gov: NCT02533817.

\section{Experimental protocol}

Each participant attended the research unit for two controlled experimental feeding days, with a washout period of 21-28 days between visits. The order of the feeding days was randomly assigned using sealed envelopes. Prior to each feeding day participants were instructed to avoid strenuous exercise and alcohol consumption in the preceding $48 \mathrm{~h}$ and fast and abstain from smoking from $10 \mathrm{pm}$ the evening before their visit. Participants were provided with a standardised meal for their evening meal prior to their visit, which provided approximately $700 \mathrm{kcals}$, with a macronutrient profile of approximately $55 \%$ carbohydrate, $30 \%$ fat, $15 \%$ protein. Participants attended the research centre at 8 am having consumed nothing other than water since $10 \mathrm{pm}$ the evening prior. During each experimental feeding day the participants were present at the research centre from 8 am until $4 \mathrm{pm}$ and consumed a standardised 24-h menu that was identical for both visits. Participants were instructed to consume only the foods and drinks provided by the research team in the $24 \mathrm{~h}$ of study. Participants returned to the research unit in a fasting state at $24 \mathrm{~h}$ for their final blood sample after which they were provided with a buffet breakfast of free choice. Participants were required to maintain sedentary behaviour whilst in the research unit and were asked to refrain from physical activity during the 24-h protocol.

Blood sampling was performed using an 18G cannula inserted into the ante-cubital fossa vein of the nondominant arm which was kept patent with saline flushes. A series of three fasting baseline blood samples were drawn at $-30,-15$ and 0 min. During the baseline period the following anthropometric measurements were performed: body weight $(\mathrm{kg})$ was measured in light clothing without shoes using digital scales (Tanita BC418MA, Toyko, Japan), height was measured to the nearest $0.5 \mathrm{~cm}$ (without shoes) using a wall-mounted stadiometer, waist circumference was measured using a flexible tape at the midpoint between the lowest rib and the iliac crest (mean of three measurements) and body composition including body fat percentage, was assessed by bioelectrical impedance (Tanita BC418MA, Toyko, Japan). Seated blood pressure was measured after a $10 \mathrm{~min}$ rest (mean of three measurements). At time 0 min participants were provided with a study breakfast (Additional file 1: Table S1) which they were required to consume within a $15 \mathrm{~min}$ period and subsequent blood samples were drawn at 15, 30, 45, $60,90,120,180,240,300,360$ and $420 \mathrm{~min}$. The lunch meal was consumed immediately following the $240 \mathrm{~min}$ blood sample and final fructose/glucose drink was consumed immediately following the $420 \mathrm{~min}$ blood sample.
A final blood sample was drawn at 24-h under fasting conditions. Each blood sample involved the removal of $2 \mathrm{~mL}$ of 'dead space' to clear the catheter tubing followed by a $10 \mathrm{~mL}$ sample into blood collection tubes containing no anticoagulant or EDTA, lithium heparin, fluoride oxalate. Samples were centrifuged (following $20 \mathrm{~min}$ clotting time for serum), divided into aliquots and stored at $-80{ }^{\circ} \mathrm{C}$ until assayed.

\section{Meals}

The menus were developed by a research dietitian to provide an energy profile of approximately $50 \%$ carbohydrate, $35 \%$ fat and $15 \%$ protein, consisting of whole foods and commercially available dishes. The nutrient composition of the menus was analysed using Food Processor software (ESHA Research, Salem, OR). The total calorie content of the menu for each individual participant was based on an estimation of the their energy requirements, which was calculated using standard equations for basal metabolic rate [26] and multiplied by a moderately sedentary physical activity ratio (1.4); these requirements were rounded up to the nearest standardised block (2200, 2500, 2900, $3200 \mathrm{kcals} /$ day). The menu was divided into 3 meals of approximately equal energy content, breakfast provided $28 \%$ of daily calories, lunch $36 \%$ and the evening meal $35 \%$. With each meal a drink containing either fructose or glucose powder was consumed which provided $25 \%$ of daily calories at breakfast and $18 \%$ of daily calories at each of the other meals, totalling $20 \%$ of calories in the 24-h period provided by added fructose or glucose; lemon flavouring was used to disguise the sweetness of the drinks. All other menu components were identical on both feeding days and participants were provided with water to drink but no other beverages (Additional file 1: Table S1). The total quantity of added glucose or fructose ranged from $110 \mathrm{~g}$ for the $2200 \mathrm{kcals}$ menu to $161 \mathrm{~g}$ for the $3200 \mathrm{kcals}$ menu. Participants were instructed to consume the fructose/glucose drink at the beginning of each meal before consuming the food dishes and instructed to consume all the foods provided. The breakfast meal was served at approximately $9.30 \mathrm{am}$, lunch was served $4 \mathrm{~h}$ later and the evening meal was packaged for participants to consume in their own home, although all the fructose/glucose drinks were consumed before the participants departed the research unit, in the presence of the research team.

\section{Laboratory analyses}

Serum triglycerides, NEFA and glucose, as well as baseline serum total and HDL cholesterol, were measured by colour photometric assays on an automated clinical chemistry analyser (ILab 650, Instrument Laboratories); serum LDLcholesterol was calculated by Friedwald equation. Serum insulin and C-peptide were determined by automated chemiluminescent immunoassay (Immulite $2000 \mathrm{XPi}$ ). 


\section{Data analysis}

Postprandial TG, NEFA, glucose, insulin and C-peptide were expressed as the area under the curve (AUC), analysed using trapedzoidal rule in Sigmaplot 12.3 (Systat Software, Inc. San Jose, CA, USA). To more accurately describe the response to feeding, the incremental AUCs (iAUC) were calculated by correction for the baseline (fasting) timepoint [27, 28]. Missing values for a given time-point $(<1.5 \%$ of all the glucose and TG values) were imputed by interpolation. The iAUC was calculated for 0-180 mins, to measure the first meal effect, and also 0-420 mins to measure the cumulative effect of first and second meals, and importantly to recognise the different post-prandial patterns of blood glucose and triglycerides.

Insulin resistance was estimated by homeostasis model assessment (HOMA-IR), calculated as [mean fasting insulin $(\mathrm{mU} / \mathrm{mL}) \times$ mean fasting glucose $(\mathrm{mmol} / \mathrm{L})] / 22.5$ [29].

Data that failed the Shapiro-Wilk normality test (plasma TG concentration) were log transformed prior to analysis. A 2-way ANOVA analysis was used to assess differences by ethnicity and treatment for biochemical time-points and iAUC comparisons. Because of the different postprandial metabolism (insulin-dependent versus non-insulin-dependent) of the 2 treatments and that glucose is an active comparator, not true control, we conducted additional statistical analysis. Comparisons between treatments within each ethnic group individually were made by paired $t$-test and comparisons between ethnic groups for each treatment (individual time points and iAUC for each outcome) were made by two-tailed independent samples $t$-test with Sidek's correction for multiple testing. Otherwise described, all data were analysed using SPSS IBM version 21 (SPSS Inc., Chicago, IL, USA).

\section{Results}

\section{Baseline characteristics}

The characteristics of the participants are shown in Table 1. Within the BA group 6 (66\%) participants were born in the UK and had resided in the UK all of their lives and 3 (33\%) participants were migrants and had resided in the UK for 10 years or longer. There were no significant differences in anthropometric and baseline characteristics between ethnic groups (Table 1), although there was a trend towards higher diastolic blood pressure in BAs. Grade 1 hypertension (140-159/90-99 $\mathrm{mmHg}$ ) was present in two WE and one BA, isolated systolic hypertension (grade 1, 140-159/<90 mmHg) was evident in one WE participant, grade 2 hypertension (160-179/100-109 $\mathrm{mmHg})$ in one BA and grade 3 hypertension $(\geq 180 / \geq 110 \mathrm{mmHg})$ in one BA. Mean BMI for both groups was within the overweight range $(\mathrm{BMI}>25)[30]$.
Table 1 Baseline anthropometric and serum biochemical characteristics of Black African and White European participants

\begin{tabular}{|c|c|c|}
\hline & $\mathrm{BA}$ & WE \\
\hline N & 9 & 11 \\
\hline Age, years & $38.3 \pm 2.0$ & $34.7 \pm 2.2$ \\
\hline Body weight, kg & $87.5 \pm 4.9$ & $80.9 \pm 4.0$ \\
\hline $\mathrm{BMI}, \mathrm{kg} / \mathrm{m}^{2}$ & $27.5 \pm 1.4$ & $25.0 \pm 1.1$ \\
\hline$W C, \mathrm{~cm}$ & $88.4 \pm 3.1$ & $90.9 \pm 2.3$ \\
\hline Body fat, $\%$ & $19.5 \pm 1.9$ & $19.7 \pm 2.1$ \\
\hline Systolic blood pressure, $\mathrm{mmHg}$ & $139 \pm 8$ & $128 \pm 6$ \\
\hline Diastolic blood pressure, $\mathrm{mmHg}$ & $87 \pm 4^{*}$ & $76 \pm 4^{*}$ \\
\hline Total cholesterol ${ }^{a}, \mathrm{mmol} / \mathrm{L}$ & $4.8 \pm 0.3$ & $4.6 \pm 0.3$ \\
\hline $\mathrm{HDL}$-cholesterol ${ }^{\mathrm{a}}, \mathrm{mmol} / \mathrm{L}$ & $1.3 \pm 0.1$ & $1.4 \pm 0.1$ \\
\hline LDL-cholesterol ${ }^{a}, \mathrm{mmol} / \mathrm{L}$ & $2.9 \pm 0.2$ & $2.7 \pm 0.2$ \\
\hline Triglycerides ${ }^{\mathrm{a}}, \mathrm{mmol} / \mathrm{L}$ & $1.09 \pm 0.15$ & $1.45 \pm 0.18$ \\
\hline $\mathrm{HOMA}-\mathrm{IR}^{\mathrm{b}}$ & $0.93 \pm 0.31$ & $0.82 \pm 0.22$ \\
\hline
\end{tabular}

Abbreviations: $B A$ Black African, $B M I$ body mass index, $H D L$ high density lipoprotein cholesterol, HOMA-IR homeostatic model assessment of insulin resistance, $L D L$ low density lipoprotein cholesterol, WC waist circumference, WE White European

Data are mean \pm SEM. $n=9(\mathrm{BA})$ and $n=11$ (WE). ${ }^{*} P<0.1$; differences between ethnic group tested by independent samples $t$-test

a Based on non-fasted serum sample

${ }^{\mathrm{b}}$ Based on fasted serum samples

\section{Fasting triglycerides}

Fasting TGs were lower in BAs than WEs on the fructose feeding day (Table 2) and neared statistical significance on the glucose feeding day. There were no other fasting differences between ethnicities.

\section{Postprandial Triglycerides and NEFA}

The 420-min time-course of glucose, TG and NEFA concentrations, after two consecutive glucose-rich or fructoserich meals, are shown in Fig. 1. The TG iAUC was higher in BAs than WEs at both iAUC ${ }_{0-180}$ and $\mathrm{iAUC}_{0-420}$ on the glucose-rich feeding day (Table 2; Fig. 1). Twenty-four hours after glucose feeding the median fasting TG were significantly increased in BA (0.84, IQR 0.61-1.20 vs 0.97, IQR $0.75-1.39 \mathrm{mmol} / \mathrm{L} ; p<0.02)$ but not WE (1.18, IQR 0.781.41 vs 1.41 , IQR $0.87-1.51 \mathrm{mmol} / \mathrm{L} ; p=0.14)$. On the fructose-rich feeding day $\mathrm{TG} \mathrm{iAUC}_{0-180}$ was greater in BAs but $\mathrm{iAUC}_{0-420}$ was not different (Table 2). Twenty-four hours after fructose feeding, the median fasting TG were no longer different between BAs (1.09, IQR 0.8-1.4 mmol/L) and WEs (1.16, IQR 0.96-1.73 mmol/L; $p=0.4)$. There was a trend for fasting TG concentrations $24 \mathrm{~h}$ following fructose feeding to increase in both BA (baseline median fasting: 0.80, IQR 0.6-1.1 vs 24-h median post-fructose: 1.09 , $0.8-1.4 \mathrm{mmol} / \mathrm{L} ; p=0.06$ ) and WE (baseline median fasting 1.10, IQR $0.9-1.5$ vs 24 -h median post-fructose: 1.16 , IQR $0.96-1.73 \mathrm{mmol} / \mathrm{L} ; p=0.06$ ). Analysis within ethnic group demonstrated that in BAs there were no differences in TG iAUC between glucose- or fructose-rich feeding regimen, 
Table 2 Fasting and postprandial glucose, NEFA, triglyceride, C-peptide and insulin response to fructose-rich or glucose-rich meals in Black African and White European participants

\begin{tabular}{|c|c|c|}
\hline & $\mathrm{BA}$ & WE \\
\hline \multicolumn{3}{|l|}{ Glucose-rich meals } \\
\hline $\begin{array}{l}\text { Fasting triglyceride, } \\
\mathrm{mmol} / \mathrm{L}\end{array}$ & $0.84(0.61-1.20)^{\mathrm{a}}$ & $1.18(0.78-1.41)^{\mathrm{a}}$ \\
\hline $\begin{array}{l}\text { Fasting triglyceride } \\
24 \mathrm{~h}, \mathrm{mmol} / \mathrm{L}\end{array}$ & $0.97(0.75-1.39)$ & $1.41(0.87-1.51)$ \\
\hline $\begin{array}{l}\text { Triglyceride iAUC } \mathrm{C}_{0-180,} \\
\mathrm{mmol} / \mathrm{L} / \mathrm{min}\end{array}$ & $35(11-56)^{a}$ & $-4(-10-1)^{a, b}$ \\
\hline $\begin{array}{l}\text { Triglyceride iAUC } 0-420 \text {, } \\
\mathrm{mmol} / \mathrm{L} / \mathrm{min}\end{array}$ & $268(77-334)^{a}$ & $39(0-111)^{a, b}$ \\
\hline $\begin{array}{l}\text { Fasting glucose, } \\
\mathrm{mmol} / \mathrm{L}\end{array}$ & $4.9 \pm 0.3$ & $5.0 \pm 0.2$ \\
\hline $\begin{array}{l}\text { Glucose iAUC } 0-180, \\
\mathrm{mmol} / \mathrm{L} / \mathrm{min}\end{array}$ & $65(-45-139)$ & $27(-18-83)$ \\
\hline $\begin{array}{l}\text { Glucose iAUC }{ }_{0-420} \\
\mathrm{mmol} / \mathrm{L} / \mathrm{min}\end{array}$ & $40(-281-251)$ & $96(-68-143)$ \\
\hline $\begin{array}{l}\text { Fasting NEFA, } \\
\mu \mathrm{mol} / \mathrm{L}\end{array}$ & $0.7 \pm 0.1$ & $0.8 \pm 0.09$ \\
\hline $\begin{array}{l}\text { NEFA iAUC } 0-180, \\
\mu \mathrm{mol} / \mathrm{L} / \mathrm{min}\end{array}$ & $-26(-48--3)^{a}$ & $-72.60(-81--52)^{a, b}$ \\
\hline $\begin{array}{l}\text { NEFA iAUC } 0-420 \text {, } \\
\mu \mathrm{mol} / \mathrm{L} / \mathrm{min}\end{array}$ & $-51(-93-96)^{a}$ & $-148.39(-164--94)^{a}$ \\
\hline $\begin{array}{l}\text { Fasting insulin, } \\
\mathrm{mU} / \mathrm{L}\end{array}$ & $4.4 \pm 1.3$ & $3.5 \pm 0.8$ \\
\hline $\begin{array}{l}\text { Insulin iAUC }{ }_{0-180,} \\
\mathrm{mU} / \mathrm{L} / \mathrm{min}\end{array}$ & 3577 (1828-5035) & 3596 (1939-4828) \\
\hline $\begin{array}{l}\text { Fasting C-peptide, } \\
\mathrm{pmol} / \mathrm{L}\end{array}$ & $424 \pm 80$ & $409 \pm 55$ \\
\hline $\begin{array}{l}\text { C-peptide iAUC }{ }_{0-180,} \\
\mathrm{pmol} / \mathrm{L} / \mathrm{min}\end{array}$ & $\begin{array}{l}188,000 \\
(112,000-259,000)\end{array}$ & $\begin{array}{l}208,000 \\
(117,000-276,000)^{b}\end{array}$ \\
\hline \multicolumn{3}{|l|}{ Fructose-rich meals } \\
\hline $\begin{array}{l}\text { Fasting triglyceride, } \\
\mathrm{mmol} / \mathrm{L}\end{array}$ & $0.80(0.6-1.1)^{\mathrm{a}}$ & $1.10(0.9-1.5)^{\mathrm{a}}$ \\
\hline $\begin{array}{l}\text { Fasting triglycerides } \\
24 \mathrm{~h}, \mathrm{mmol} / \mathrm{L}\end{array}$ & $1.09(0.80-1.54)$ & $1.16(0.96-1.73)$ \\
\hline $\begin{array}{l}\text { Triglyceride } \mathrm{A}_{\mathrm{AUC}} \mathrm{C}_{0-180} \\
\mathrm{mmol} / \mathrm{L} / \mathrm{min}\end{array}$ & $48(15-68)^{a}$ & $13(-7-38)^{a, b}$ \\
\hline $\begin{array}{l}\text { Triglyceride iAUC } 0-420 \text {, } \\
\mathrm{mmol} / \mathrm{L} / \mathrm{min}\end{array}$ & $217(139-279)^{a}$ & $162(37-219)^{a, b}$ \\
\hline $\begin{array}{l}\text { Fasting glucose, } \\
\mathrm{mmol} / \mathrm{L}\end{array}$ & $4.8 \pm 0.2$ & $5.1 \pm 0.1$ \\
\hline $\begin{array}{l}\text { Glucose iAUC } 0-180, \\
\mathrm{mmol} / \mathrm{L} / \mathrm{min}\end{array}$ & $-2(-109-50)$ & $-11(-147-69)$ \\
\hline $\begin{array}{l}\text { Glucose iAUC } 0-420, \\
\mathrm{mmol} / \mathrm{L} / \mathrm{min}\end{array}$ & $-149(-318-61)$ & $-60(-204-138)$ \\
\hline $\begin{array}{l}\text { Fasting NEFA, } \\
\mu \mathrm{mol} / \mathrm{L}\end{array}$ & $0.8 \pm 0.1$ & $0.7 \pm 0.1$ \\
\hline $\begin{array}{l}\text { NEFA iAUC } 0-180, \\
\mu \mathrm{mol} / \mathrm{L} / \mathrm{min}\end{array}$ & $-33(-51-12)$ & $-40(-64--30)^{b}$ \\
\hline $\begin{array}{l}\text { NEFA iAUC }{ }_{0-420,} \\
\mu \mathrm{mol} / \mathrm{L} / \mathrm{min}\end{array}$ & $-51(-96-46)$ & $-77(-124--10)$ \\
\hline
\end{tabular}

Table 2 Fasting and postprandial glucose, NEFA, triglyceride, C-peptide and insulin response to fructose-rich or glucose-rich meals in Black African and White European participants (Continued)

\begin{tabular}{|c|c|c|}
\hline $\begin{array}{l}\text { Fasting insulin, } \\
\mathrm{mU} / \mathrm{L}\end{array}$ & $3.3 \pm 1.3$ & $3.5 \pm 0.5$ \\
\hline $\begin{array}{l}\text { Insulin iAUC }{ }_{0-180,} \\
\mathrm{mU} / \mathrm{L} / \mathrm{min}\end{array}$ & 1710 (831-3975) & $2318(863-3276)$ \\
\hline $\begin{array}{l}\text { Fasting C-peptide, } \\
\mathrm{pmol} / \mathrm{L}\end{array}$ & $329 \pm 60$ & $399 \pm 49$ \\
\hline $\begin{array}{l}\text { C-peptide iAUC } 0-180, \\
\mathrm{pmol} / \mathrm{L} / \mathrm{min}\end{array}$ & $\begin{array}{l}101,940 \\
(68,708-148,140)\end{array}$ & $\begin{array}{l}110,340 \\
(80,753-175,901)^{b}\end{array}$ \\
\hline \multicolumn{3}{|c|}{$\begin{array}{l}\text { Abbreviations: BA Black African, iAUC incremental area under the curve, NEFA } \\
\text { non-esterified fatty acids, WE White European } \\
\text { Data mean } \pm \text { SEM or median (IQR), } n=9(\mathrm{BA}) \text { and } n=11 \text { (WE) } \\
\text { anotes within treatment difference between ethnic group tested by } \\
\text { independent samples } t \text {-test, } P<0.05 \\
\text { benotes within ethnic group difference between treatment tested by paired } \\
t \text {-test, } P<0.05\end{array}$} \\
\hline
\end{tabular}

however in WEs, there were trends towards greater TG iAUC at iAUC ${ }_{0-180}(p=0.053)$ and at iAUC $0-420(p=0.076)$ with fructose-rich feeding than with glucose-rich feeding. In both ethnic groups the NEFA concentration following feeding was suppressed to levels below the fasting value, leading to negative AUCs at 180 and 420 min (Table 2; Fig. 1). Greater suppression of postprandial NEFA was evident in WEs after glucose-rich feeding than in $\mathrm{BAs}$ at $\mathrm{iAUC}_{0-180}$ and $\mathrm{iAUC}_{0-420}$. No ethnic difference in NEFA suppression was seen after fructose-rich feeding.

\section{Postprandial glucose}

There were no differences between ethnicities in peak glucose concentration or glucose iAUC (Table 2; Fig. 1). In WEs, peak glucose was at 45-min with glucose-rich feeding and $30 \mathrm{~min}$ with fructose-rich feeding and there were no differences in plasma glucose concentration at any time point. In BAs, peak glucose was after 30-min with glucose-rich feeding and at 45-min with fructose-rich feeding. In BAs, plasma glucose was greater at 120-min ( $4.72 \pm 0.48$ vs $4.04 \pm 0.41 \mathrm{mmol} / \mathrm{L} ; P=0.003)$ and at 300 $\min (5.91 \pm 0.38$ vs $4.83 \pm 0.23 \mathrm{mmol} / \mathrm{L} ; P=0.004)$ with glucose-rich feeding compared to fructose-rich feeding. Cpeptide and insulin concentrations were not different, between ethnicities, on either feeding day (Table 2; Fig. 2); specifically, the peak response, incremental response and iAUC were similar. As expected, in both ethnic groups, glucose-rich feeding led to higher insulin and C-peptide responses than fructose-rich feeding (Fig. 2). Peak C-peptide response occurred after $60 \mathrm{~min}$ in both ethnic groups and with both types of feeding. Peak insulin occurred after 30-min in both ethnicities with a glucose-rich meal but after 60-min with a fructose-rich meal. There was no significant interaction between ethnicity and feeding regimen, tested by two-way ANOVA, on glucose or lipid responses to glucose-rich or fructose-rich feeding. 

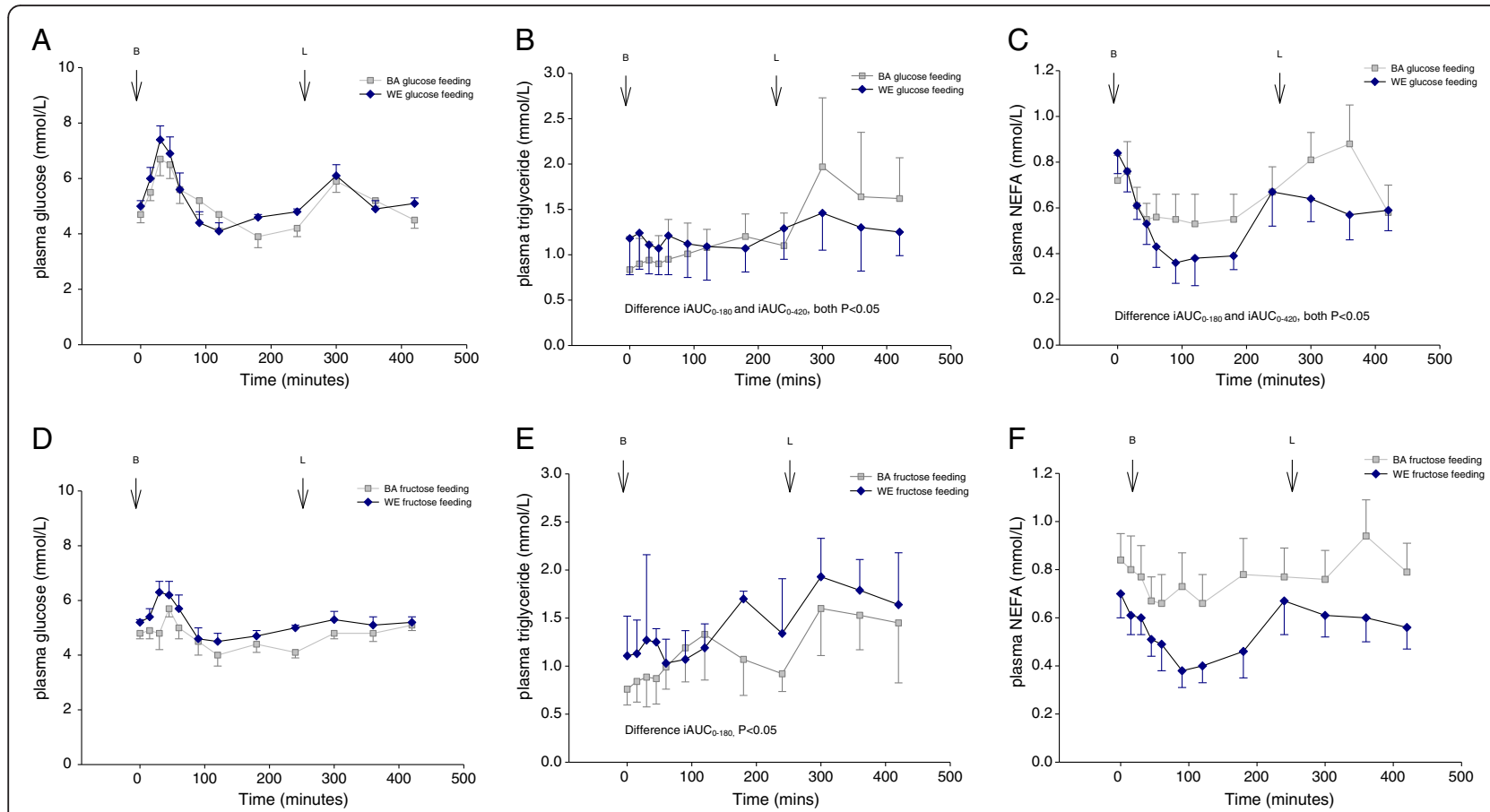

Fig. 1 Serum glucose (a), TG (b) and NEFA (c) response to glucose-rich meals in BA (light square) and WE (dark diamonds) participants, and serum glucose $(\mathbf{d})$, triglyceride $(\mathbf{e})$ and NEFA (f) response to fructose-rich meals in BA (light square) and WE (dark diamonds) participants. Breakfast meal consumed at 0 min and lunch meal consumed following the 240 min sample. Point estimates are mean \pm SEM for glucose and NEFA, and median (IQR) for triglyceride. Light squares: BA; dark diamonds; WE. BA, Black African; NEFA, non-esterified fatty acids; TG, triglyceride; WE, White European

\section{Discussion}

To our knowledge this pilot investigation is the first to examine ethnic specific effects of fructose feeding and demonstrates markedly greater TG excursions in BA participants compared to WEs in response to high fructose and high glucose intakes, despite significantly lower fasting TGs.

Low fasting TG concentrations have been extensively reported in populations of African ancestry [1,31,32] and are proposed to contribute to the protection from coronary artery disease $(\mathrm{CAD})$ that they exhibit $[4,5]$. However recent data have demonstrated that this cardio-protection has been lost amongst younger populations [6,7] and Blacks no longer exhibit lower TGs than Whites [8]. In our study, BA men were found to have lower fasting TGs at baseline but not different to the WEs $24 \mathrm{~h}$ post fructose treatment (Table 2). This suggests that consumption of high fructose loads may have detrimental effects on fasting lipids in people of African ancestry. Traditionally the African and Caribbean diet is not high in added sugar [33] however recent USA data suggests that consumption of added sugar is higher amongst African-Americans than Whites [25], and in our own UK data we have demonstrated that in Black Caribbean adults sugar-sweetened beverages and confectionary are the 5th and 8th most important contributors to energy intake, respectively [14]. Interestingly 'Westernisation' of the diet is much less evident in those whose migration is more recent [14] and indeed these less acculturated communities still exhibit lower fasting TGs [8] and may still be protected from CAD. The majority of the BA participants in the present study were born in the UK, and those who weren't had resided in the UK for a significant length of time, therefore their diet is likely to have undergone significant acculturation. However, the lower fasting triglycerides that were evident suggest there is still some level of cardioprotection amongst this group.

Post-prandial lipid handling has not been previously investigated in this ethnic group despite the growing body of evidence to show their importance as indicators of a proatherogenic state [34, 35]. Our data suggest that in response to both glucose and fructose BAs exhibited a marked hypertriglyceridemia, which may help to explain some of the detrimental health outcomes associated with consumption of high sugar diets. We are not able to determine the exact mechanisms driving this hypertriglyceridemic response, for example the relative contributions of increased hepatic secretion of TG-rich very low density lipoprotein (VLDL) and decreased TG clearance (predominantly into adipose tissue). Recent tracer studies have shown increased chylomicron production rates in patients with the metabolic syndrome [36] but to our knowledge, no comparative data exist of chylomicron production rates between ethnicities. It is noteworthy that following glucose 


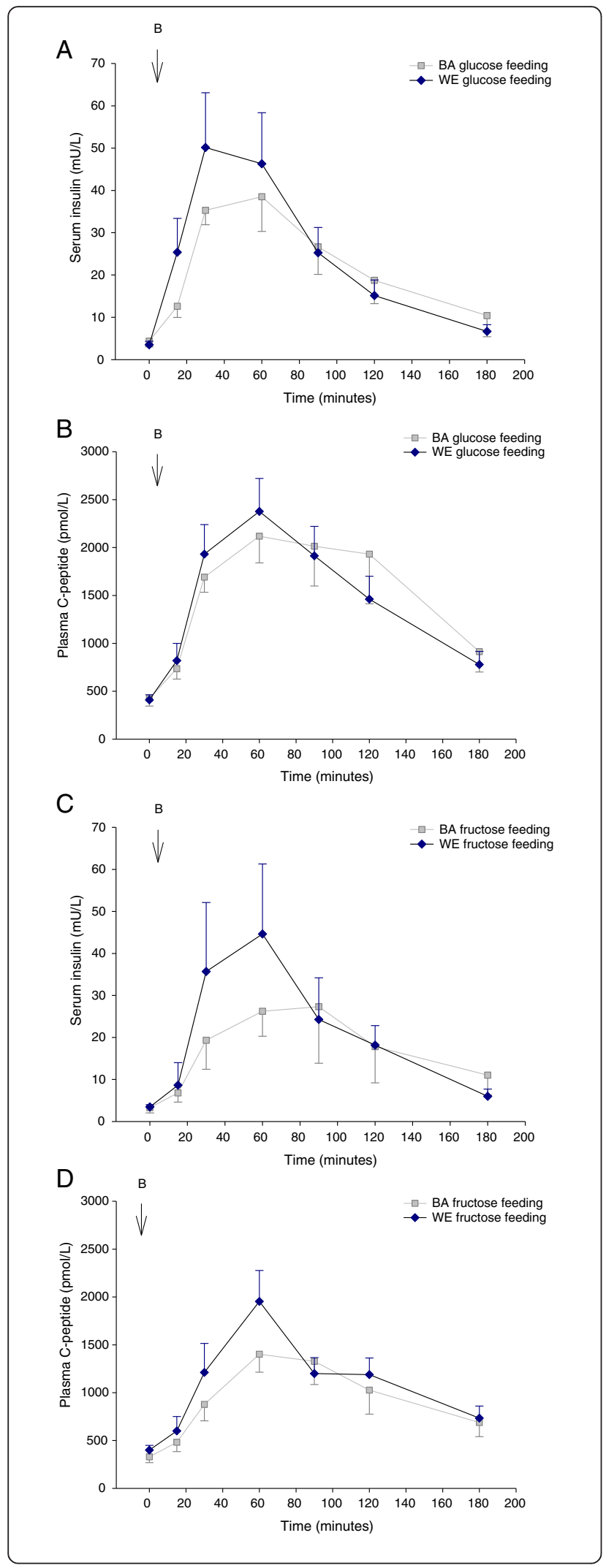

Fig. 2 Serum insulin (a) and C-peptide (b) response to glucose-rich meals in BA (light square) and WE (dark diamonds) participants, and serum insulin (c) and C-peptide (d) response to fructose-rich meals in BA (light square) and WE (dark diamonds) participants. Breakfast meal consumed at 0 min. Point estimates are mean \pm SEM. Light square: BA; dark diamonds: WE. BA, Black African; WE, White European

feeding suppression of NEFA was significantly less in the BA than the WE participants potentially providing greater substrate availability for VLDL-TG secretion. The reduced NEFA suppression by the BA participants, despite similar insulin secretion and circulating insulin concentrations, allows us to speculate that there is a greater adipocyte insulin resistance in the BAs, despite no differences in HOMA index of whole body insulin resistance between ethnicities. If greater adipocyte insulin resistance is indeed the case it may have led to reduced TG clearance, contributing to the hypertriglyceridaemic response that we observed.

The strengths and limitations of our study warrant consideration. This investigation was a pilot study involving a small number of participants however we used tightly controlled conditions to study the ethnic specific metabolic effects of acute high fructose and glucose feeding. Our participants were closely matched with no differences in age, BMI or waist circumference, which are important determinants of lipid metabolism and cardiovascular risk and therefore we are confident that our differences are mainly ethnicity based. We do however acknowledge the broad range in age and BMI of our participants, which may have contributed to heterogeneity in our data. Our BA participants exhibited higher blood pressure and lower fasting TGs, which was to be expected given the extensive literature that reports this cardiometabolic profile amongst people of African ancestry $[37,38]$. Our feeding protocol was informed by, and comparable with the literature [21, 22]; it provided $20 \%$ of daily energy as added glucose or fructose in the form of a drink, which was ingested alongside a menu of usual dietary items that provided an overall nutrient composition (approximately $50 \%$ carbohydrate, $35 \%$ fat and $15 \%$ protein) similar to the UK diet and was not expected to invoke significant post-prandial lipemia. Our participants were provided with a standardised meal for the evening meal preceding the feeding days in an attempt to standardise the 'second meal' metabolic effect. In agreement with the literature [22, 39] we demonstrated a significantly lower glucose, insulin and C-peptide response to fructose feeding compared to glucose, which gives us confidence in the design of our protocol; furthermore the participants consumed the menus in the presence of the investigators and therefore we are confident that we achieved a high level of compliance. Our sample size was small and our protocol studied only short term effects of high sugar consumption, however we believe we have generated 
persuasive initial data to demonstrate ethnicity specific metabolic effects that warrant further investigation in a large scale, longer term trial. This study did not involve use of isotope tracer techniques which would have enabled us to investigate in detail the mechanisms by which dietary sugars promote hypertriglyceridemia and future investigations should include these methods. Additionally stable isotope studies with adipose and muscle tissue biopsies and more in depth analysis of body composition, particularly visceral fat deposits, could be used to investigate further our hypothesis that the failure to suppress NEFAs amongst the BA participants may be as a result of intensified adipocyte insulin resistance.

\section{Conclusions}

In conclusion these pilot data illustrate the short term metabolic effects of acute high added fructose and high added glucose feeding in healthy men of BA ethnicity. In particular, this study reports significant postprandial hypertriglyceridemia in men of BA ethnicity compared to men of WE ethnicity. These subtle but distinct ethnic differences in the postprandial handing of high added sugar is an important consideration for future study of ethnic specific risk in disease cardiometabolic disease development. Finally, while preliminary, these data describe a metabolic response to high sugar feeding in the postprandial period that may influence the process of dietary acculturation and Westernisation, which occurs in Black communities. Therefore, the postprandial response to high fructose and glucose feeding is important to consider in the study of cardiometabolic risk development in different ethnicities.

\section{Additional file}

Additional file 1: Nutritional composition of the experimental feeding day standardised menu (2500 kcal/day), providing $20 \%$ energy as added glucose or fructose. (DOCX $12 \mathrm{~kb}$ )

\section{Acknowledgements}

The authors would like to thank Annika Coombes, Joseph Took, David Simms, Obena Ofori-Sey, and Nicole Birch who assisted with conducting the research and data collection. We are also grateful to Anne-Catherine Perz for her assistance with the laboratory analysis.

\section{Funding}

This study was funded by a small academic grant from King's College London.

\section{Availability of data and materials}

All datasets generated and analysed during this study are available from the corresponding authors upon email request.

\section{Authors' contributions}

LMG \& SVH designed research, conducted research, wrote the manuscript and had primary responsibility for final content. MS conducted research and analysed data. MW analysed data and performed statistical analysis and wrote manuscript. All authors have read and approved the final manuscript.

\section{Competing interests}

LMG, no competing interests. MW, no competing interests. MS, no competing interests. SVH, has received honorarium and/or consulted for The Dairy Council UK, Seven Seas (Merck KGaA) and Manitoba Starch Products.

\section{Ethics approval and consent to participate}

The study was approved and conducted according to the standards of the King's College London Research Ethics Committee (BDM-12-13-7), and written informed consent was provided by all participants.

\section{Author details}

'Division of Diabetes and Nutritional Sciences, King's College London, Franklin-Wilkins Building, Stamford Street, London SE1 9NH, UK. ${ }^{2}$ Department of Diabetes and Metabolic Medicine, University of Surrey, Wolfson Unit for Translational Research, Postgraduate Medical School, Daphne Jackson Road, Guildford GU2 7WG, UK. ${ }^{3}$ Division of Diabetes and Nutritional Sciences, King's College London, Henriette Raphael Building, Room 2.29, Guy's Campus, London SE1 1UL, UK.

Received: 28 May 2016 Accepted: 26 August 2016

Published online: 02 September 2016

\section{References}

1. Zoratti R, Godsland IF, Chaturvedi N, Crook D, Stevenson JC, McKeigue PM. Relation of plasma lipids to insulin resistance, nonesterified fatty acid levels, and body fat in men from three ethnic groups: relevance to variation in risk of diabetes and coronary disease. Metabolism. 2000;49:245-52.

2. Chaturvedi N, McKeigue PM, Marmot MG. Relationship of glucose intolerance to coronary risk in Afro-Caribbeans compared with Europeans. Diabetologia. 1994;37:765-72

3. Singh GK, Siahpush M. Ethnic-immigrant differentials in health behaviors, morbidity, and cause-specific mortality in the United States: an analysis of two national data bases. Hum Biol. 2002;74:83-109.

4. Tillin T, Forouhi NG, McKeigue PM, Chaturvedi N. The role of diabetes and components of the metabolic syndrome in stroke and coronary heart disease mortality in U.K. white and African-Caribbean populations. Diabetes Care. 2006;29:2127-9.

5. Wild S, McKeigue P. Cross sectional analysis of mortality by country of birth in England and Wales, 1970-92. BMJ. 1997;314:705-10.

6. Jolly S, Vittinghoff E, Chattopadhyay A, Bibbins-Domingo K. Higher cardiovascular disease prevalence and mortality among younger blacks compared to whites. Am J Med. 2010;123:811-8.

7. Ferdinand KC. Coronary artery disease in minority racial and ethnic groups in the United States. Am J Cardiol. 2006;97:12A-9.

8. Donin AS, Nightingale CM, Owen CG, Rudnicka AR, McNamara MC, Prynne CJ, Stephen AM, Cook DG, Whincup PH. Ethnic differences in blood lipids and dietary intake between UK children of black African, black Caribbean, South Asian, and white European origin: the Child Heart and Health Study in England (CHASE). Am J Clin Nutr. 2010;92:776-83.

9. Saab KR, Kendrick J, Yracheta JM, Lanaspa MA, Pollard M, Johnson RJ. New insights on the risk for cardiovascular disease in African Americans: the role of added sugars. J Am Soc Nephrol. 2015;26:247-57.

10. Sharma S, Wilkens $L R$, Shen $L$, Kolonel $L N$. Dietary sources of five nutrients in ethnic groups represented in the Multiethnic Cohort. Br J Nutr. 2013;109:1479-89.

11. Satia JA. Dietary acculturation and the nutrition transition: an overview. Appl Physiol Nutr Metab. 2010;35:219-23.

12. Anderson SG, Younger N, Heald AH, Tulloch-Reid MK, Simukonda WP, Mbanya JC, Jackson MD, Balkau B, Sharma S, Tanya A, et al. Nutrient intakes and dysglycaemia in populations of West African origin. Br J Nutr. 2011;105:297-306.

13. Satia-Abouta J, Patterson RE, Neuhouser ML, Elder J. Dietary acculturation: applications to nutrition research and dietetics. J Am Diet Assoc. 2002;102:1105-18.

14. Goff $L M$, Timbers $L$, Style $H$, Knight A. Dietary intake in Black British adults; an observational assessment of nutritional composition and the role of traditional foods in UK Caribbean and West African diets. Public Health Nutr. 2014;1-11.

15. Marriott BP, Cole N, Lee E. National estimates of dietary fructose intake increased from 1977 to 2004 in the United States. J Nutr. 2009;139:1228S-35.

16. Gibney M, Sigman-Grant M, Stanton Jr JL, Keast DR. Consumption of sugars, Am J Clin Nutr. 1995;62:178S-93. discussion 194S.

17. Chong MF, Fielding BA, Frayn KN. Mechanisms for the acute effect of fructose on postprandial lipemia. Am J Clin Nutr. 2007;85:1511-20. 
18. Abraha A, Humphreys SM, Clark ML, Matthews DR, Frayn KN. Acute effect of fructose on postprandial lipaemia in diabetic and non-diabetic subjects. Br J Nutr. 1998;80:169-75.

19. Faeh D, Minehira K, Schwarz JM, Periasamy R, Park S, Tappy L. Effect of fructose overfeeding and fish oil administration on hepatic de novo lipogenesis and insulin sensitivity in healthy men. Diabetes. 2005;54:1907-13.

20. Le KA, Faeh D, Stettler R, Ith M, Kreis R, Vermathen P, Boesch C, Ravussin E, Tappy L. A 4-wk high-fructose diet alters lipid metabolism without affecting insulin sensitivity or ectopic lipids in healthy humans. Am J Clin Nutr. 2006;84:1374-9.

21. Abdel-Sayed A, Binnert C, Le KA, Bortolotti M, Schneiter P, Tappy L. A high-fructose diet impairs basal and stress-mediated lipid metabolism in healthy male subjects. Br J Nutr. 2008;100:393-9.

22. Stanhope KL, Griffen SC, Bair BR, Swarbrick MM, Keim NL, Havel PJ. Twenty-fourhour endocrine and metabolic profiles following consumption of high-fructose corn syrup-, sucrose-, fructose-, and glucose-sweetened beverages with meals. Am J Clin Nutr. 2008:87:1194-203.

23. Stanhope KL, Schwarz JM, Keim NL, Griffen SC, Bremer AA, Graham JL, Hatcher B, Cox CL, Dyachenko A, Zhang W, et al. Consuming fructose-sweetened, not glucose-sweetened, beverages increases visceral adiposity and lipids and decreases insulin sensitivity in overweight/obese humans. J Clin Invest. 2009; 19:1322-34.

24. Tran C, Jacot-Descombes D, Lecoultre V, Fielding BA, Carrel G, Le KA, Schneiter P, Bortolotti M, Frayn KN, Tappy L. Sex differences in lipid and glucose kinetics after ingestion of an acute oral fructose load. Br J Nutr. 2010;104:1139-47.

25. Yang $Q$, Zhang Z, Gregg EW, Flanders WD, Merritt R, Hu FB. Added sugar intake and cardiovascular diseases mortality among US adults. JAMA Intern Med. 2014;174:516-24.

26. Henry CJ. Basal metabolic rate studies in humans: measurement and development of new equations. Public Health Nutr. 2005;8:1133-52.

27. Le Floch JP, Escuyer P, Baudin E, Baudon D, Perlemuter L. Blood glucose area under the curve. Methodological aspects. Diabetes Care. 1990;13:172-5.

28. Carstensen M, Thomsen $C$, Hermansen $K$. Incremental area under response curve more accurately describes the triglyceride response to an oral fat load in both healthy and type 2 diabetic subjects. Metabolism. 2003:52:1034-7.

29. Matthews DR, Hosker JP, Rudenski AS, Naylor BA, Treacher DF, Turner RC. Homeostasis model assessment: insulin resistance and beta-cell function from fasting plasma glucose and insulin concentrations in man. Diabetologia. 1985;28:412-9

30. Global Database on Body Mass Index [http://apps.who.int/bmi/index jsp?introPage=intro_3.html]. Accessed 27 May 2016.

31. Sumner $A E$, Cowie CC. Ethnic differences in the ability of triglyceride levels to identify insulin resistance. Atherosclerosis. 2008;196:696-703.

32. Goff LM, Griffin BA, Lovegrove JA, Sanders TA, Jebb SA, Bluck LJ, Frost GS. Ethnic differences in beta-cell function, dietary intake and expression of the metabolic syndrome among UK adults of South Asian, black African-Caribbean and white-European origin at high risk of metabolic syndrome. Diab Vasc Dis Res. 2013;10:315-23.

33. Sharma S, Cade J, Jackson M, Mbanya JC, Chungong S, Forrester T, Bennett F, Wilks R, Balkau B, Cruickshank JK. Development of food frequency questionnaires in three population samples of African origin from Cameroon, Jamaica and Caribbean migrants to the UK. Eur J Clin Nutr. 1996;50: 479-86.

34. Stalenhoef AF, de Graaf J. Association of fasting and nonfasting serum triglycerides with cardiovascular disease and the role of remnant-like lipoproteins and small dense LDL. Curr Opin Lipidol. 2008:19:355-61.

35. Nordestgaard BG, Benn M, Schnohr P, Tybjaerg-Hansen A. Nonfasting triglycerides and risk of myocardial infarction, ischemic heart disease, and death in men and women. JAMA. 2007;298:299-308.

36. Shojaee-Moradie F, Ma Y, Lou S, Hovorka R, Umpleby AM. Prandial hypertriglyceridemia in metabolic syndrome is due to an overproduction of both chylomicron and VLDL triacylglycerol. Diabetes. 2013;62:4063-9.

37. Chaturvedi N, Marmot MG, McKeigue PM. Racial differences and hypertension. BMJ. 1994;308:1634-5.

38. Chaturvedi N, McKeigue PM, Marmot MG. Resting and ambulatory blood pressure differences in Afro-Caribbeans and Europeans. Hypertension. 1993; 22:90-6.

39. Stanhope KL, Griffen SC, Bremer AA, Vink RG, Schaefer E, Nakajima K, Schwarz JM, Beysen C, Berglund L, Keim NL, Havel PJ. Metabolic responses to prolonged consumption of glucose- and fructose-sweetened beverages are not associated with postprandial or 24-h glucose and insulin excursions. Am J Clin Nutr. 2011;94: $112-9$.

\section{Submit your next manuscript to BioMed Central and we will help you at every step:}

- We accept pre-submission inquiries

- Our selector tool helps you to find the most relevant journal

- We provide round the clock customer support

- Convenient online submission

- Thorough peer review

- Inclusion in PubMed and all major indexing services

- Maximum visibility for your research

Submit your manuscript at www.biomedcentral.com/submit 